\section{Lower GI tract - basic}

\section{OXV/1 1126}

BASIC GENE EXPRESSION OF OPIOID PEPTIDES IN HUMAN GASTROINTESTINAL TRACT.

P. Di Sebastiano, M. Buechler, T. Fink* M.K.H. Schaefer ${ }^{*}, E$. Weihe,$H$. Friess and H.G. Beger. Departments of Surgery and *Anatomy, University of Uim and Mainz, Germany.

The distribution of opioid peptides in the gastro-intestinal (GI) tract has been characterized by immunohistochemistry in a variety of species including man. In contrast, the pattern of opioid gene expression in the GI-tract is still unknown. AIM OF THE STUDY: based on this consideration it was the aim of this study to evaluate the presence of the three opioid precursors proenkephalin (PRO-ENK), prodynorphin (PRO-DYN) and proopiomelanocort in. (POMC) at the mRNA level.

MATERIALS AND METHODS: Fresh frozen tissue obtained from 20 patients undergoing small and large bowel resection was studied using in situ hybridization with 35 S-labelled CRNA probes. We focused on normal human colon and small intestine and only normal tissue regions (histology) were processed for analysis.

RESULTS: In human colon and small intestine, the majority of neurons in the myoenteric plexus expressed PRO-ENK mRNA at extremely high levels. In contrast, expression "of PRO-ENK mRNA in the submucosal plexus. was not observed. PRO-DYN mRNA was expressed at low levels in a minor subpopulation of myoenteric neurons in the human gut. In addition, a large number of cells in the epithelium of the small intestine expressed PRO-OYN MRNA. POMC MRNA gene expression was below detection level.

CONCLUSIONS: The selective presence of PRO-ENK in the majority of myoenteric neurons indicates that PRO-ENK is of major importance in the intrinsic neuronal regulation of gut major importance in the intrinsic neuronal regulation of gut myoenteric neurons suggests that intrinsic dynorphin is of minor importance or may more selectively modulate neuroregulation of gut functions. On the other hand, PRO-DYN may be the only opioid precursor that is involved in paracrine or autocrine functions in neuroendocrine cells in the epithelium. The absence of detectable POMC levels is in contrast to immunocytochemical data ad may indicate that POMC plays no major role in neural or neuroendocrine functions of the GI-tract.

Supported by the German Minister for Research and Technology.

\section{OXV/3 1108}

INTERLEUKIN-6 MODULATES THE SUPPRESSIVE EFFECंT OF INTERLEUKIN-1 ON NEUROTRANSMITTER RELEASE FROM RAT MYENTERIC PLEXUS. A.Ruehl, S.M.Collins. Intestinal Diseases Research Unit, McMaster University, Hamilton, Ontario, Canada.

Intestinal inflammation is accompanied by motility changes which reflect altered function of enteric smooth muscle and myenteric plexus. This may be cytokine-mediated, as some cytokines (IL-1 $\beta, \mathrm{TNF} \alpha$ ) have been shown to alter enteric nerve function. Furthermore, we have demonstrated an increased expression of mRNA for a variety of inflammatory cytokines in the muscle layers of the nematode-infected rat intestine, including interleukin-1 $\beta$ (IL-1 $\beta$ ) and interleukin-6 (IL-6). Observations in other biological systems that cytokines often act synergistically prompted us to examine interdependency of cytokine-effects in the myenteric plexus. Specifically, we have examined the interactions between IL- $1 \beta$ and IL- 6 on ${ }^{3} \mathrm{H}$-noradrenaline $\left({ }^{3} \mathrm{H}-\mathrm{NA}\right)$ release from longitudinal muscle-myenteric plexus (LM-MP) from jejunum of non-infected rats.

LM-MP preparations were loaded with ${ }^{3} \mathrm{H}-\mathrm{NA}$ prior to electrical field stimulation at $30 \mathrm{~V}, .10 \mathrm{~Hz}, 0.5 \mathrm{~ms}$ for $1 \mathrm{~min}$ and ${ }^{3} \mathrm{H}-\mathrm{NA}$ release was measured. Tissues were preincubated with hrIL-6 $(10-100 \mathrm{ng} / \mathrm{ml})$ or a subthreshold dose $(0.1 \mathrm{ng} / \mathrm{ml})$ of hrIL- $1 \beta$ for 45,90 or $120 \mathrm{~min}$. IL- 6 alone had no effect on ${ }^{3} \mathrm{H}-\mathrm{NA}$ uptake or release under these conditions. Similarly, there was no suppressive effect of IL- $1 \beta$ when preincubated alone with the tissue. However, when the two cytokines were preincubated together for $120 \mathrm{~min}$, there was a significant $33 \%$ suppression of ${ }^{3} \mathrm{H}-\mathrm{NA}$ release. Antihuman IL-6 neutralizing antibody or IL-1 $\beta$ receptor antagonist $(10 \mu \mathrm{g} / \mathrm{ml})$ abolished the suppression. The suppressive effect was also abolished by the protein synthesis inhibitor cycloheximide $(100 \mu \mathrm{g} / \mathrm{ml})$. To examine the involvement of intermediary cells, we investigated the effect of cyclosporin A $(5 \mu \mathrm{g} / \mathrm{ml})$. Preincubation of the tissue with this immunosuppressive agent attenuated the suppressive effect of IL- $1 \beta$ and IL- 6 .

These results indicate that IL- 6 potentiates the suppressive effect of IL-1 $\beta$ on ${ }^{3} \mathrm{H}-\mathrm{NA}$ release in the myenteric plexus. Furthermore, the data sugges that this effect is mediated by a protein, probably synthesized by macrophage-like cells located in the myenteric plexus. Thus this work further elucidates the mechanisms by which the function of the enteric nervous system is modulated by the immune systern.

Supported by DFG Ru 528/1-1 and MRC Canada.
IN HUMAN COLON 5-HT, AND 5-HT -LIKE RECEPTORS SUBSERVE RELAXATION. F. Tam, K. Hillier, K. T. Bunce', C. Grossman'. Clinical Pharmacology, University of Southampton; 'Glaxo Group Research (UK).

5-HT inhibits spontaneous contractions in the circular muscle (CM) of human colon through a novel $5-\mathrm{HT}_{4}$ receptor. We have furcher characterised this receptor and have also found that the receptor in the longitudinal muscle (LM) is $5-\mathrm{HT}_{1}$-like. Tension in LM or CM surips from ascending or sigmoid colon was recorded isometrically in Krebs gassed with $95 \% \mathrm{O}_{2}, 5 \% \mathrm{CO}_{2}$ at $37^{\circ} \mathrm{C}$ and $15 \mathrm{mN}$ tension. Each result is the mean $\pm \operatorname{sem}(n=6-8)$. In $\mathrm{LM}$ agonists were added as separate doses $(0.01-100 \mu \mathrm{M})$ for $2 \mathrm{~min}$; relaxation in basal tone was measured. Fifteen minutes were left between doses. In CM, agonist effects on spontaneous contractions were measured when added cumulatively $(0.01-100 \mu \mathrm{M})$ with a $2 \mathrm{~min}$ contact time. Antagonists were incubated for $30 \mathrm{~min}$ before adding agonists. In LM, 5carboxamidotryptamine $(5-\mathrm{CT})$, a potent $5-\mathrm{HT}_{1}$-like agonist, caused a maximum relaxation of only $32.7 \pm 2.17 \%$ of the relaxation induced by

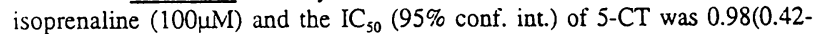
2.22) $\mu \mathrm{M}$ of its own maximum response. The effect was abolished by a 5 $\mathrm{HT}_{1} / 5-\mathrm{HT}_{2}$ antagonist. methysergide, but not a $5-\mathrm{HT}_{2}$ antagonist. ketanserin and $5-\mathrm{HT}_{3}$ antagonist, ondansetron. The effect of $5-\mathrm{HT}(0.01-100 \mu \mathrm{M})$ was, however, variable. It elicited either relaxation, contraction or biphasic effect. For those strips which relaxed in the presence of 5-HT, the maximum response was only $17.3 \pm 1.07 \%$ of the isoprenaline-induced relaxation and the mean $\mathrm{IC}_{50}$ was $5.73(3.48-9.01) \mu \mathrm{M}$. In $\mathrm{CM}, 5-\mathrm{HT}$ and the $5-\mathrm{HT}_{4}$ receptor agonist benzimidozolones (BIMU8 and BIMU1) elicited inhibition of the spontaneous contractions (expressed as a percentage reduction of amplitude measured before drug addition) with an $\mathrm{IC}_{50}$ of $0.13(0.04-0.42) ; 0.76(0.10$ $5.91)$ and $3.19 \cdot(0.32-32.1) \mu \mathrm{M}$ respectively. DAU6285 (a benzimidazolone) antagonised the 5-HT-induced inhibition with a $\mathrm{pA}_{2}$ of $6.32 \pm 0.30$ (slope $=$ $0.84)$. The Schild slope was not significantly different from 1 . The recently discovered $5-\mathrm{HT}_{4}$ receptor antagonist. GR113808, is being investigated and in 2 patients studied thus far has a pAn value of 8.54 (slope $=0.99$ ). It was concluded that 5-HT inhibits the motility of $\mathrm{CM}$ via $5-\mathrm{HT}_{4}$ and $\mathrm{LM}$ via a 5 $\mathrm{HT}_{1}$ receptor. This has important implications for the physiological and therapeutic control of human gastrointestinal motility.

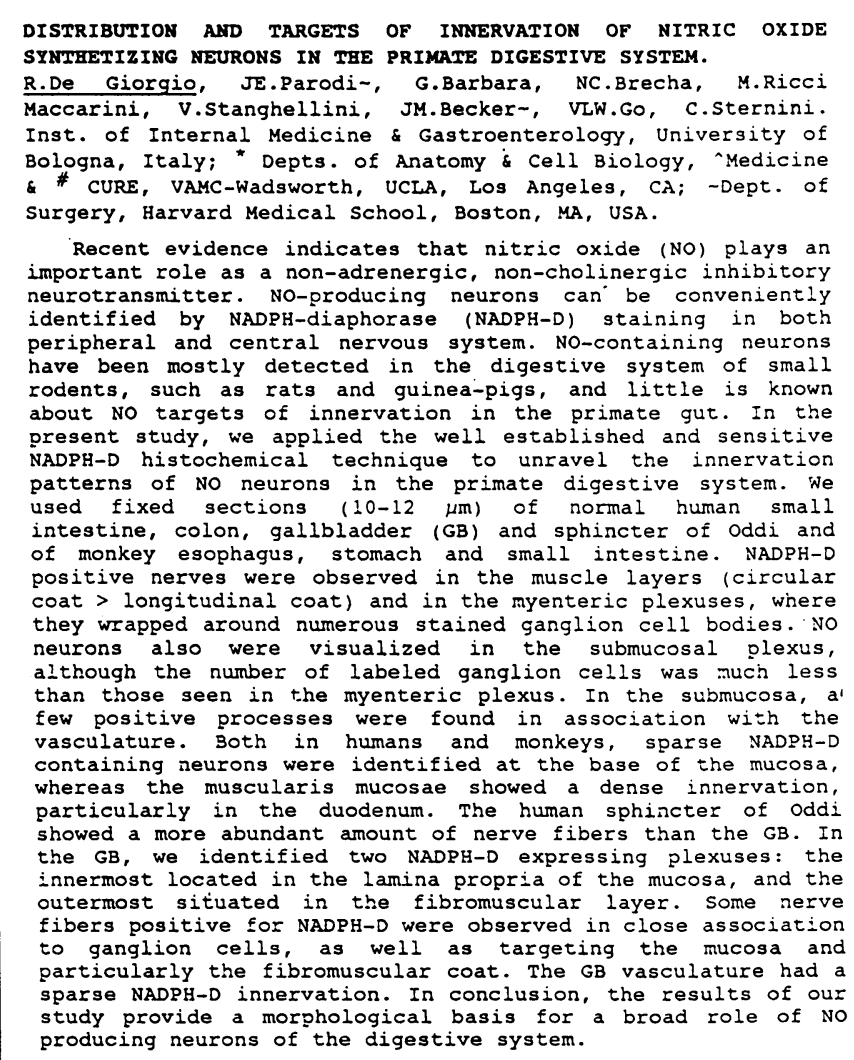

DISTRIBUTION AND TARGETS OF INNERVATION OF NITRIC OXIDE R.De Giorgio, JE.Parodir, G.Barbara, NC.Brecha, M.Ricci Maccarini, V.Stanghellini, JM.Becker-, VLW.Go, C.Sternini. Inst. of Internal Medicine \& Gastroenterology, University of Bologna, Italy; Depts. of Anatomy \& Cell Biology, Medicine surgery, Harvard Medical School, Boston, MA, USA.

de (NO) plays a as a non-adrenergic, non-cholinergic inhibitory identified by NADPH-diaphorase (NADPH-D) staining in both peripheral and central nervous system. NO-containing neurons have been mostly detected in the digestive system of small about No targets of innervation in the primate gut. In the present study, we applied the well established and sensitive Distochemical technique to unravel the innervation used $f$ ixed sections $(10-12 \mu \mathrm{m})$ of normal human small intestine, colon, gallbladder (GB) and sphincter of oddi and positive nerves were observed in the muscle layers (circular coat > longitudinal coat) and in the myenteric plexuses, where they wrapped around numerous stained ganglion cell bodies. NO neurons also were visualized in the submucosal plexus, than those few positive processes were found in association with the containing peurons were identified at the base of the mucosa, wheras the particularly in the duodenum. The human sphincter of oddi showed a more abundant amount of nerve fibers than the GB. In innermost located in the lamina propria of the mucosa, and the outermost situated in the fibromuscular layer. Some nerve to ganglion cells, as well as targeting the mucosa and particularly the fibromuscular producing neurons of the digestive system. 
OXV/5 328

NITRIC OXME SYNTHASE INHIBITION LEADS TO SEVERE BOWEL ISCHAEMIA AND WATER SECRETION: AN IN VTVO STUDY IN RAT JEJUNUM FH Mourad, LDD O'Donnell, RA Owen, MI Clark, MJG Farthing. Dept. of Gastroenterology, St Bartholomew's Hospital, London EClA 7BE, and Dept. of Histopathology, Whipps Cross Hospital, London E11.

Nitric oxide (NO) maintains vascular integrity in endotoxin-induced acute intestinal damage, but its role in maintaining basal small intestinal physiological function and its relation to blood flow has not been studied in vivo. We have investigated the implications of NO synthase inhibition on physiologic and histologic changes in rat jejunum in vivo.

The NO synthase inhibitor nitro L-Arg methyl ester (L-NAME) $(100 \mathrm{mg} / \mathrm{kg}$ ) was administered sc to male adult Wistar rats. $20 \mathrm{~min}$ later a $25 \mathrm{~cm}$ segment of jejunum was perfused in vivo with iso-osmotic saline containing $\left[{ }^{14} \mathrm{C}\right]-\mathrm{PEG}$. After $30 \mathrm{~min}$ of perfusion, $3 \times 10 \mathrm{~min}$ collections of the effluent were obtained to assess water movement. Samples of small intestine were taken at the end of the experiments for histopathological examination. In a parallel group of animals, L-Arg or D-Arg $(500 \mathrm{mg} / \mathrm{kg}$ ) was given sc $15 \mathrm{~min}$ prior to L-NAME injection. Controls were given either L-Arg, D-Arg or saline without LNAME

Marked water secretion occured after L-NAME administration (median $-34 \mu \mathrm{l} / \mathrm{min} / \mathrm{g}$ dry intestinal weight [interquartile range -45 to -18$], \mathrm{n}=10$ ) as compared to water absorption in saline control ( 17 [ 2 to 35 ], $n=15 ; p<0.01)$ The secretory state was attenuated by pretreatment with $L-\operatorname{Arg}(-4[-17$ to 6$]$ $n=5 ; p<0.05$ compared to L-NAME alone), but not with D-Arg (-41 [-51 to -19], $n=5 ;$ NS). L-Arg or D-Arg alone had no effect on basal water movement (30 [14 to 38] and 25 [15 to 28], respectively, $n=5$ ). In the L-NAME treated animals, there was macroscopic and microscopic intestinal ischaemia with vascular congestion and haemorrhage accompanied by early degenerative changes of the surface epithelium. These changes could be prevented by pretreatment with L-Arg but not D-Arg.

Thus, NO appears to play an important role in maintaining small intestina physiologic function and circulation and its inhibition leads to severe bowel ischaemia and water secretion.

\section{OXV/6 405}

CORTICOSTEROID REGULATION OF $\mathrm{Na}^{+} / \mathrm{K}^{+}$ATPase SUBUNIT GÉNE EXPRESSION IN THE COLON: MODULATION BY $11 \beta$-HYDROXYSTEROID DEHYDROGENASE C.B. Whorwood and P.M Stewart, Department of Medicine, Queen Elizabeth Hospital, Edgbaston, Birmingham B15 2TH, UK.

$11 \beta$-Hydroxysteroid dehydrogenase (11 $\beta$-HSD) is a microsomal enzyme which catalyses the interconversion of active glucocorticoid (GC), cortisol, to inactive metabolite, cortisone (corticosterone (B) to 11-dehydroB in rodents). This is the mechanism by which specificity is conferred upon the mineralocorticoid receptor (MR) and also by which ligand access to the glucocorticoid receptor (GR) is modulated. Deficiency of $11 \beta$-HSD following eg. licorice (glycyrrhizic acid, Gl) ingestion results in physiological GC acting as a potent mineralocorticoid (MC). The colon is an important $M C$ target tissue, $\mathrm{Na}^{+} / \mathrm{K}^{+}$ATPase activity across which is increased following inhibition of $11 \beta-\mathrm{HSD}$. $\mathrm{Na}^{+} / \mathrm{K}^{+}$ATPase, a basolateral sodium pump, maintains an electrochemical gradient. It comprises a catalytic $a_{1}$ subunit and a $\beta$, subunit of unknown function but debate continues as to whether they are regulated by $M C$ or $G C$.

We have measured $\mathrm{Na}^{+} / \mathrm{K}^{+}$ATPase $a_{1}(3.7 \mathrm{~Kb}), \beta_{1}(2.3 \& 2.7 \mathrm{~Kb})$ subunit and $11 \beta$-HSD (1.4 \& 3.4Kb) mRNA levels (Northern blot analysis) and $11 \beta$ HSD activity (\%B to 11-dehydroB, HPLC) in the rat distal colon.

Normal adult male wistar rats ( $n=6 /$ group) received either GI ( $>75 \mathrm{mg} / \mathrm{Kg} / \mathrm{day}$ ) or the antagonists $(8 \mathrm{mg} / \mathrm{Kg} /$ day) for MC, RU26752 or GC RU38386 alone or a combination of GI and RU analogs for 4 days. $a_{1}$ and $\beta$, mRNA levels (mean $\pm \mathrm{SE}$ ). were reduced following treatment with both RU analogs alone: $\sigma_{1}$, control $7.8+1.1$ vs $3.6+0.9$ (RU752, $\left.p<0.05\right)$ vs $4.4+0.2$ (RU $486, p<0.05$ ): and $\beta$, control $11.3+1.1$ vs $4.0+0.9$ (RU752 $p<0.001$ ) vs $6.0 \pm 0.5$ (RU486, $p<0.005$ ). Gl reduced levels of $11 \beta$-HSD mRNA and activity $(1.8 \pm 0.5$ vs $16.9 \pm 0.9 \& 26 \pm 2 \%$ vs $35 \pm 3 \%$, $\mathrm{p}<0.001)$ irrespective of the presence of RU752 $(3.5 \pm 1.0 \& 24.1 \pm 1.2 \%)$ or RU486 $(3.7+1.2 \& 23.8+0.9 \%)$ but GI (vs control) had no significant effect on mRNA levels for either $\alpha_{1}(4.6+0.7$ vs $7.2+0.7)$ or $\beta_{1}(13.9+1.8$ vs $15.2 \pm 2.4)$. However, $a, 1 \beta$, mRNA levels declined significantly in the presence of Gl \& RU $486\left(a_{1}: 2.9 \pm 0.4\right.$ vs $7.2 \pm 0.7, p<0.01 \& \beta_{1}: 5.9 \pm 0.9$ vs $15.2 \pm 2.4, p<0.0011$, but were unaltered following G1 \& RU752.

$\mathrm{Na}^{+} / \mathrm{K}^{+}$ATPase $a$, and $\beta$, subunit mRNA levels in the distal colon are regulated by both $M C$ and $G C$ mechanisms but not $G 1$ in vivo. However. following direct $\mathrm{Gl}$ inhibition of $11 \beta$-HSD gene expression, the marked decline in $\sigma_{1} / \beta$, mRNA levels in the presence of RU486, but not RU752. indicates that under conditions of un-hindered $G C$ access to both $M R$ and $G R, a, / \beta$, expression is regulated principally via the GR.

\section{OXV/7 415}

INVOLVEMENT OF CAPSAICIN-SENSITIVE SENSORY NEURONS IN THE INTESTINAL EFFECTS OF CLOSTRIDIUM DIFFICILE TOXIN A, BUT NOT CHOLERA TOXIN. A. Jaffer, I. Castagliuolo, C.P. Relly, J.T. LaMont, c. Pothoulakis. Section of Gastroenterology, Boston University School of Medicine, Boston, MA, USA.

c. difficile toxin A ( $T \times A$ ) causes acute inflammation and fluid secretion when injected into ileal loops. Vibrio cholerae enterotoxin (CT) also causes fluid secretion, but does not produce intestinal inflammation or damage. Since primary sensory neurons have been involved in intestinal inflammation, this study was undertaken to compare the contribution of primary sensory neurons on TXA and CTmediated intestinal effects in rat ileum. Methods: Rats were pretreated with capsaicin (primary sensory neuron desensitizer, $35 \mathrm{mg} / \mathrm{kg} /$ day for 3 days, sc with a two week rest before subsequent experimentation). Rat ileal loops were injected with either 5 ug of TXA or 25 ug of CT or buffer (control) ( $n=8$ for each group). After 3 hours enterotoxicity was assessed by fluid secretion $(\mathrm{ul} / \mathrm{cm}$ ) and by blood-to-lumen excretion of $3 \mathrm{H}$-mannitol $(\mathrm{dpm} / \mathrm{cm})$. Mucosal mast cell (MMC) degranulation after treatment with IXA was evaluated by measuring rat mast cell protease II (RMCP II) a specific marker for MMC in mesenteric venous blood
after injection of TxA. Results: As expected, TXA stimulated fluid secretion ( 3.3 -fold over control, $p<0.01$ ) and mannitol permeability ( 9.5 -fold over control, $p<0.05$ ) pretreatment of rats with capsaicin significantly reduced TxA induced fluid secretion (by $77.9 \%, p<0.01$ ) and mannitol permeability (by 79.2z, p<0.01). However, pretreatment with capsaicin did not alter the effect of CT on either fluid secretion or mannitol permeability. Mesenteric venous blood from loops injected with TXA had significantly higher RMCPII levels than blood from control groups $(n=5, p<0.01)$ and pretreatment of animals with capsaicin, completely abolished this increase $(n=3, p<0.01)$. Summary and Conclusions: 1 ) Capsaicin-sensitive sensory afferent neurons are involved in TXA but not CT mediated secretion 2) Mast cell degranulation caused by TxA may be regulated by sensory neurons.

\section{OXV/8 1136}

SLOW RELEASE LANREOTIDE IN CARCINOID SYNDROME. P. Ruszniewski (1), F. Thomas (2), P. Rougier (3), E. Genestin (2), D. Cloarec (4), H. Gouerou (5), H. Michel (6), R Modigliani (7), JA. Chayvialle (8). Hospital Beaujon Paris (1), Ipsen Biotech (2), Institut

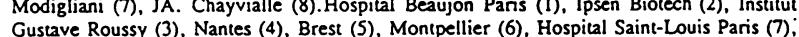
Lyon (8)

Lanreotide (L)(somatuline, Ipsen Biotech) is an octapeptide analogue of somatostatin which partially inhibits the endocrine and exocrine secretion of the gut in man and has antiproliferative properties. A slow release formulation which contains $30 \mathrm{mg}$ of lanreotide in polymere microspheres has been designed for every other week intramuscular injection.

Pacients and methods: Twenty nine patients were enrolled in a French multicentre tria (mean age : $64 \pm 10$; sex : $16 \mathrm{M}, 13 \mathrm{~F}$ ). All tumors originated from the gut (except 3 from lung and 1 from prostate), 27 were metastatic. Twelve patients had been previously treated with chemotherapy, 5 with interferon, 6 with embolization and 12 with octreotide (mean dose $413 \mu \mathrm{g}$ (range 100-1,200); mean duration : 626 days (range : 19-2,487)]. A minimum 3 day wash-out period between octreotide and $\mathrm{L}$ was requested (mean 67.5 days). Patients were followed at day 7, 15, 29 and monthly thereafter.

Results : The efficacy on symptoms (Partial Regression $=$ PR or Complete Regression $=$ $\mathrm{CR}$ ) and markers (PR = more than $30 \%$ decrease in serotonin and SHIAA) at day 7 and at day 90 (or last value carried forward = LVCF) are reported for the $n$ patients with an abnormal symptom or marker before $L$ treatment.

\begin{tabular}{l|l|l} 
& \multicolumn{1}{|c|}{$\mathrm{D} 7$} & \multicolumn{1}{c}{$\mathrm{D} 90$ (on LVCF) } \\
\hline Flushing $(\mathrm{n}=21)$ & $\mathrm{PR}=7 ; \mathrm{CR}=11$ & $\mathrm{PR}=6 ; \mathrm{CR}=9$ \\
\hline Diarrhea $(\mathrm{n}=23)$ & $\mathrm{PR}=11 ; \mathrm{CR}=4$ & $\mathrm{PR}=10 ; \mathrm{CR}=6$ \\
\hline Abdominal pain $(\mathrm{n}=13)$ & $\mathrm{PR}=4 ; \mathrm{CR}=4$ & $\mathrm{PR}=4 ; \mathrm{CR}=6$ \\
\hline Urinary 5HIAA $(\mathrm{n}=27)$ & $\mathrm{PR}=12(\mathrm{n}=24)$ & $\mathrm{PR}=11(\mathrm{n}=27)$ \\
\hline Serotonin $(\mathrm{n}=24)$ & $\mathrm{PR}=8(\mathrm{n}=21)$ & $\mathrm{PR}=10(\mathrm{n}=24)$
\end{tabular}

Non parametric tests were used for comparison and $p<0.05$ was chosen as the level of Non parametric tests were used for comparison and $p<0.05$ was chosen as the level of
significance. The iniensity of flushing, diarrhea and abdominal pain and the number of significance. The intensity of flushing, diarthea and abdominal pain and the number
flushes and bowel movements were significantly reduced by $L$. There was no difference in eificacy of $L$ between the groups who had received octreotide or not. The efficacy of $L$ and eificacy of $L$ between the groups who had received octreotide or not. The efficacy of $L$ and octreotide were similar although one patient controlled by octreotide did not respond to
Serotonin but not SHIAA (at the exception of day 7) was significantly.decreased by L. Serotonin but not SHIAA (at the exception of day 7) was significantly. decreased by L.
Measurable Tumors were followed by CT Scan every 3 months. Two out of the 16 evaluable Measurable Tumors were followed by CT Scan every 3 months. Two out of the 16 eval
patients had a more than $50 \%$ reduction (PR) in the size of their liver metastases.

Conclusion : This study suggests that the slow release formulation of $L$ injected every other week is a convenient and useful treatment of patients with carcinoid syndrom. 